\title{
Relationships between serum leptin and bone markers during stable weight, weight reduction and weight regain in male and female judoists
}

\author{
S Prouteau ${ }^{1,2}$, L Benhamou ${ }^{1,2}$ and D Courteix ${ }^{1,2}$ \\ ${ }^{1}$ Bone Tissue Architecture and Physical Exercise (ATOSEP Laboratory), University of Orleans, Orleans, France and ${ }^{2}$ Laboratory of Bone Tissue \\ Characterisation and Imaging, INSERM Unit 658, Orleans Regional Hospital, Orleans, France \\ (Correspondence should be addressed to S Prouteau, at IPROS-INSERM U 658, C.H.R Orleans-1, rue Porte Madeleine, B.P 2439, 45032 Orleans Cedex \\ 1, France; Email: stephanie.prouteau@chr-orleans.fr)
}

\begin{abstract}
Objective: Despite a preliminary understanding of leptin-skeletal interactions, data in humans are inconsistent and the exact roles of leptin on bone metabolism have not yet been defined. The aim of this study was to examine the possible role of leptin in the regulation of bone metabolism in healthy, physically trained adults.

Methods and Design: Body composition and bone mass (dual-energy X-ray absorptiometry), anthropometry, serum leptin, insulin, cortisol, osteocalcin, C-terminal telopeptide of type I collagen (CTx) and total plasma proteins were measured in judoists at normal body weight, after weight reduction and after weight regain. Physical training, weight cycling history, menstrual status and nutritional intake using a 7-day food record were assessed.

Results: Precompetitive weight loss averaged $4 \pm 0.3 \%$ of bodyweight and resulted in a significant decrease in leptin levels of $64 \%(P<0.001)$ and of $31 \%$ for insulin $(P<0.0001)$. CTx and cortisol concentrations rose by 33\% $(P<0.0001)$ and $81 \%(P<0.05)$ respectively. Osteocalcin and total plasma protein remained unaffected by weight loss. A $4 \pm 0.5 \%$ weight regain induced a $276 \%$ increase in leptin levels $(P<0.001)$ and an $18 \%$ increase in insulin $(P<0.001)$. CTx and cortisol decreased by $23 \%(P<0.0001)$ and $27 \%(P<0.05)$ respectively. Changes in leptin were significantly correlated with changes in bone resorption marker in response to both weight loss $(r=0.56, P<0.01)$ and regain $(r=0.44, P<0.05)$.

Conclusions: These findings suggest that leptin is involved in the regulation of bone metabolism in healthy adults and might play a potential role in the prevention of osteoporosis.
\end{abstract}

European Journal of Endocrinology 154 389-395

\section{Introduction}

Leptin is a cytokine protein encoded by the $o b$ gene and secreted from adipose tissue (1). Circulating levels have been shown to be positively associated with fat mass in both lean and obese individuals $(2,3)$. Leptin first emerged as a component of a regulatory loop linking fat mass to food intake and energy expenditure (4) but recently raised considerable interest as a potential mediator of the protective effects of fat mass on bone tissue.

Both a peripheral and a central action of leptin on bone metabolism have been proposed. Peripherally, leptin is thought to exert positive effects on bone formation, whereas it is thought to reduce bone formation via a central control mechanism when binding to its specific receptors located on the hypothalamic nuclei (5). Despite a preliminary understanding of leptin-skeletal interactions, the exact roles of leptin on bone metabolism have not yet been clarified. Data in the literature are inconsistent and conflicting. In vitro, leptin has been shown to exert direct osteotrophic effects by promoting differentiation of bone marrow stromal cells into osteoblasts (6) and by inhibiting osteoclast generation (7). These data have been confirmed in different animal models, with peripheral leptin administration having positive effects on bone by modulating formation and resorption processes (8). In sum, in vitro and in vivo evidence support the hypothesis that leptin has the ability to act directly on bone remodelling by modulating both osteoblast and osteoclast activities. However, studies in humans have not been able to confirm these actions. 
The objective of the present study was to test the hypothesis of a potential role of leptin in the regulation of bone metabolism in healthy adults. Based on the assumption that disturbances in the physiological systems may help to shed further light on these interrelationships, bone biomarkers, leptin, insulin, cortisol and body composition were assessed under conditions of stable weight, weight loss and weight regain in healthy athletes.

Judo is a combat sport with strict competitive weight categories. In order to qualify for their respective weight category, many contestants undergo drastic food restriction in the week preceding the competition. The amount of weight thus lost is subsequently regained as the athletes compensate for the sustained energy drain by excess food intake (9). This rapid alternation between weight loss and regain is known as weight cycling. For the purpose of this study, a cohort of judoists was recruited and tested three times: first, during stable weight conditions, secondly, after a week of food restriction resulting in significant weight loss and, finally, 3 weeks later with bodyweight regain. To take into account possible gender differences, both male and female subjects were included.

\section{Materials and methods}

\section{Experimental design}

The judoists in this study were tested three times during the judo season: first, in October, when they were all at their normal weight (early season; ES). The second measure took place upon completion of 7 days of severe food restriction, when precompetitive weight loss was achieved (precompetition; Pre-C). Thus, Pre-C testing took place $24 \mathrm{~h}(48 \mathrm{~h}$ in three judoists leaving for competition abroad), prior to the first 'inweight' competition of the season (Pre-C, in March). The third measure was taken 3 weeks after Pre-C testing when the judoists had regained the weight previously lost (post-competition; Post-C). Judoists who were within the limits of their competitive weight category did not have to loose weight to qualify for competition. Judoists who varied in weight (weight cyclers; WC) and those who did not vary in weight (non cyclers; NC) underwent the same rigorous testing procedures. Anthropometry, bone mass, body composition and biochemical parameters were assessed at each testing period.

\section{Subjects}

Fifty-four elite judoists at the French national training camp in Orleans (France) volunteered to participate in this study. Four dropped out of the study because of failure to meet testing schedules due to frequent trips abroad for competitive needs or transfer to another university. Two further judoists were excluded because of severe injury sustained during training.
Judoists (age $20 \pm 3.0$ years; 22 men and 26 women) had been training for $13 \pm 4$ years and their weekly training volume $(9.5 \pm 3 \mathrm{~h} /$ week $)$ had been constant over the past 3 years. There were no differences between male and female judoists with regard to any of these training variables. This study analysed the first weight cycle of the judo season. This research project was undertaken after approval by the regional Human Ethics Committee of the University of Tours Medical School, which is the Institutional Review Board for all biomedical studies conducted in our region (Region Centre, France). All participants received a verbal and written description of the research protocol and each subject gave written informed consent. None of the subjects reported taking any medications, diuretics, protein supplements or creatine monohydrate. Exclusion criteria were occurrence of fracture within the last 24 months, failure to comply with the entire protocol and interruption of training for more than 2 weeks.

\section{Assessment of bone mass and body composition}

Total and regional bone mineral content (BMC), bone mineral density (BMD) and soft tissue composition were measured by dual-energy X-ray absorptiometry with a Hologic QDR 4500 (Hologic Inc., Waltham, MA, USA). Regional bone measurements comprised the lumbar spine (including L1 to L4) and the nondominant proximal femur (including femoral neck, greater trochanter and intertrochantic region). According to the World Health Organisation (10), the T-score represents the BMD of the individuals compared with the normal peak value of young adults. Soft tissue composition comprised fat mass and lean body mass (LBM). All scans were performed and analysed by the same operator in order to limit inter-observer variability. The coefficient of variation in our laboratory is $0.84 \%$ for $\mathrm{BMD}, 1.2 \%$ for $\mathrm{BMC}, 3.9 \%$ for fat mass and $0.48 \%$ for LBM measurements.

\section{Blood sampling and analysis}

The subjects were instructed to refrain from performing strenuous exercise (intense training session) $48 \mathrm{~h}$ prior to the visit to the laboratory, to avoid any kind of physical activity on the morning of blood sampling and to follow the same pretesting procedures before each visit. After an overnight fast, resting blood samples were obtained by antecubital venipuncture in a sitting position. Blood was drawn strictly between 0800 and $0900 \mathrm{~h}$. Identical testing procedures were rigorously controlled for at each testing period. Blood samples were centrifuged and distributed into aliquots adequate for analysis of each bone marker and hormone. All samples were then immediately frozen at $-80^{\circ} \mathrm{C}$ until analysis. Serum leptin was measured using the Duoset ELISA kit (R\&D 
Systems, Inc., Mineapolis, MN, USA). Intra- and interassay coefficients of variation (CV) were $6.5 \%$ and $9.3 \%$ respectively. The minimal detectable limit was $20 \mathrm{pg} / \mathrm{ml}$. Serum insulin was determined with the EASIA insulin kit (BioSource Europe S.A., Nivelles Belgium). Intra- and interassay $\mathrm{CV}$ values were $4.2 \%$ and $7.0 \%$ respectively, and the detection limit was $0.15 \mu \mathrm{IU} / \mathrm{ml}$. C-terminal telopeptide of type I collagen (CTx) assays were performed with the ELISA CrossLaps kit (Nordic Bioscience Diagnostics, Herlev, Denmark). Intra- and interassay CV values were $5.2 \%$ and $6.7 \%$ respectively, and the detection limit was $0.010 \mathrm{ng} / \mathrm{ml}$. Osteocalcin measurements were made with the NMID Osteocalcin ELISA kit (Nordic Bioscience Diagnostics). Intra- and interassay CV values were $2.6 \%$ and $4.7 \%$ respectively, with a detection limit of $0.5 \mathrm{ng} / \mathrm{ml}$. Cortisol concentrations were measured by ELISA (Immuno-Biological Laboratories, Hamburg, Germany). Intra- and interassay CV values were $5.6 \%$ and $6.9 \%$ respectively, and the detection limit was $2.5 \mathrm{ng} / \mathrm{ml}$. Total plasma protein concentration, used as indices of dehydration (11), was determined by the Biuret method (12), with a measurement error of $<2 \%$. All concentrations were determined as the average of duplicate determinations. To minimize the effects of assay variability, samples from each subject were analysed in the same assay.

\section{Physical activity and lifestyle}

The judoists were questioned regarding their training and weight cycling history. Confirmation of these variables was obtained from medical records and training logs. Average daily macro- and micronutrient intake were calculated from a 7-day food record (including weekend days) using the software Prodiet 5.2a (Proform, Arnouville les Gonesse, France), which uses the Ciqual database (13). Nutritional assessments were made at ES during normal food intake. Nutritional intake during the 7 days of food restriction were not assessed because of the limited availability of the judoists and also because some subjects were reluctant to record drastic food restriction. Female judoists were interviewed regarding their menstrual status, age of menarche (first menses) and use of oral contraception. Amenorrhea in this study was defined as absence of menses for at least 6 consecutive months before the beginning of the study. All interviews and questionnaires were administered by the same researcher.

\section{Statistical analyses}

Normal distribution of the data was tested by the Kolmogorov-Smirnov test. In order to accurately assign the judoists into their respective $\mathrm{WC}$ or $\mathrm{NC}$ group, a typological classification was performed using the method of aggregation around a mobile centre. The variables entered into this multivariate analysis were the amount of weight lost and subsequently regained.
Influence of gender on the typological classification was tested with a chi-square test. Statistical differences between groups were determined by an unpaired $t$-test. Between-group comparisons of anthropometric, biochemical and training variables were made with oneway ANOVA. Changes in anthropometric and biological parameters over the three testing periods (ES, Pre-C and Post-C) were assessed by repeated measures of ANOVA with a $2 \times 2$ factorial design based on gender (male/female) or group (WC/NC). A Newman-Keuls post hoc analysis was used to locate statistical significance when an ANOVA was significant. Analysis of covariance was used to adjust circulating leptin concentrations for body fat and regression analyses were used to evaluate associations among different variables. Statistical significance was accepted at $P<0.05$. All statistical analyses were performed by PCSM statistical software (Optima-Deltasoft, Merignac, France). Data are presented as means \pm S.E. unless specified otherwise.

\section{Results}

\section{Baseline characteristics}

Table 1 describes the baseline characteristics of male and female judoists. Table 2 presents baseline biochemical parameters. Female judoists had higher levels of cortisol and lower CTx than their male counterparts. Osteocalcin levels appeared to be greater in males, though this difference did not reach significance. The adipocyte hormone leptin was, as expected, higher in females than in males but this difference no longer held when leptin was adjusted for percentage body fat.

\section{Nutritional intake}

Table 3 summarizes the nutritional intake of the judoists. Energy intake as well as carbohydrate, fat and protein intake were significantly greater in males than in females. However, the distribution of macronutrient in $\%$ of daily energy intake was similar in both genders. Males consumed more calcium than their female counterparts, but vitamin D intake was similar in both genders and revealed no pre-existing deficits. For

Table 1 Characteristics of the judoists at baseline. Values are means \pm S.D.

\begin{tabular}{lcc}
\hline & Male $(n=22)$ & Female $(n=26)$ \\
\hline Age (years) & $20.9 \pm 3.4$ & $19 \pm 2.4$ \\
Weight $(\mathrm{kg})$ & $73.6 \pm 8.3$ & $60.3 \pm 9.1$ \\
Body mass index & $24 \pm 2.1$ & $22.7 \pm 2.4$ \\
LBM $(\mathrm{kg})$ & $61.6 \pm 5.8$ & $43.7 \pm 5.1$ \\
FM $(\%)$ & $11.6 \pm 3.6$ & $23 \pm 4.1$ \\
Total BMD $\left(\mathrm{g} / \mathrm{cm}^{2}\right)$ & $1.40 \pm 0.1$ & $1.21 \pm 0.07$ \\
T-score $(\%)$ & $119 \pm 8$ & $113 \pm 7$ \\
Lumbar BMD $\left(\mathrm{g} / \mathrm{cm}^{2}\right)$ & $1.28 \pm 0.13$ & $1.14 \pm 0.08$ \\
Hip BMD $\left(\mathrm{g} / \mathrm{cm}^{2}\right)$ & $1.29 \pm 0.11$ & $1.10 \pm 0.11$ \\
\hline
\end{tabular}


Table 2 Baseline biochemical parameters. Values are means \pm S.E.

\begin{tabular}{lcc}
\hline & Male $(n=22)$ & Female $(n=26)$ \\
\hline Osteocalcin $(\mathrm{ng} / \mathrm{ml})$ & $52.5 \pm 5.5$ & $45.3 \pm 3.0$ \\
CTx $(\mathrm{ng} / \mathrm{ml})$ & $0.857 \pm 0.04$ & $0.728 \pm 0.03^{*}$ \\
Leptin $(\mathrm{pg} / \mathrm{ml})$ & $1412 \pm 295$ & $6062 \pm 864^{*}$ \\
Leptin $(\mathrm{adjusted}$ for \% body fat) & $4587 \pm 449$ & $3375 \pm 367$ \\
Insulin $(\mu \mathrm{lU} / \mathrm{ml})$ & $10.0 \pm 0.6$ & $9.7 \pm 0.4$ \\
Cortisol $(\mathrm{ng} / \mathrm{ml})$ & $118 \pm 7$ & $160 \pm 14^{*}$ \\
Total plasma proteins $(\mu \mathrm{g} / \mathrm{ml})$ & $367 \pm 20$ & $336 \pm 10$ \\
\hline
\end{tabular}

${ }^{*} P<0.05$ compared with males.

both genders, calcium and vitamin D intakes were within the French recommended dietary allowances (14). Daily energy intake, macronutrients, calcium and vitamin $\mathrm{D}$ were each unrelated to biochemical or bone parameters respectively.

\section{Menstrual cycle characteristics}

Three female judoists were currently amenorrheic at the time of the study but these women did not have a history of menstrual cycle disturbances. The remaining females were all menstruating regularly and none reported any history of menstrual cycle disturbances. Among these, 12 were taking oral contraceptives. The type used was low dose oestrogen and progestin combined oral contraceptive, and none was taking antiandrogens. There were no differences in biochemical parameters and body composition between the women who were amenorrheic, eumenorrheic or taking oral contraceptives.

\section{Weight cycling}

The typological classification test classified the population into WCs $(n=19)$ or NCs $(n=29)$. Gender had no influence on the typological classification into WCs or NCs. WCs experienced a $4 \pm 0.3 \%$ bodyweight loss during the week leading up to the competition (Pre-C) followed by a $4 \pm 0.5 \%$ weight gain at Post-C. On the contrary, NCs maintained unchanged weight and biochemical values throughout the season. This study analysed

Table 3 Mean daily nutritional intake. Values are means \pm S.E.

\begin{tabular}{lcc}
\hline & Male $(n=22)$ & Female $(n=26)$ \\
\hline Energy intake (kcal/day) & $2960 \pm 135$ & $2121 \pm 132^{*}$ \\
CHO $(\mathrm{g})$ & $362 \pm 21$ & $245 \pm 17^{*}$ \\
$\mathrm{CHO}$ in \% of energy intake & $50 \pm 2$ & $47 \pm 1$ \\
Fat $(\mathrm{g})$ & $124 \pm 10$ & $93 \pm 7^{*}$ \\
Fat in \% of energy intake & $37 \pm 2$ & $39 \pm 1$ \\
Proteins $(\mathrm{g})$ & $94 \pm 6$ & $66 \pm 3^{*}$ \\
Proteins in \% of energy intake & $13 \pm 0.5$ & $13 \pm 0.5$ \\
Calcium $(\mathrm{mg})$ & $1403 \pm 113$ & $1015 \pm 83^{\star}$ \\
Vitamin D $(\mu \mathrm{g})$ & $11.3 \pm 1.9$ & $9.7 \pm 1.0$ \\
\hline
\end{tabular}

${ }^{\star} P<0.05$ compared with males. the first weight cycle of the judo season. Prior to this study, WCs reported a history of weight cycling of $3.2 \pm 1.5$ years. Unless specified otherwise, the results revealed no significant difference between genders and led to the pooling of male and female data.

\section{Correlations between baseline endocrine and bone parameters}

Leptin was positively associated with percentage body fat $(r=0.63, P<0.001$ in females and $r=0.71$, $P<0.0001$ in males) but was related to body mass index in females only $(r=0.46, P<0.05)$. No association between leptin and weight emerged in either gender. In both genders, a history of weight cycling had no influence on leptin levels. In females, but not in males, CTx levels were inversely related to leptin $(r=0.41, P<0.05)$. Osteocalcin was positively associated with CTx levels in both males $(r=0.63$, $P<0.001)$ and females $(r=0.39, P<0.05)$. In both genders, baseline circulating leptin showed no relation with osteocalcin, insulin or cortisol levels. Since insulin levels were no different between genders, only BMD values were corrected for the effects of gender in the regression analysis. The latter revealed a positive association between baseline insulinaemia and BMD at the Ward's triangle $(r=0.64, P<0.01)$ and femur $(r=0.62, \quad P<0.01)$ respectively. Regression analysis indicated that leptinaemia was not related to BMD at any site in men and women alone or in combination after correcting for the effects of sex.

\section{Effects of weight loss and regain on anthropometric parameters}

Repeated measures ANOVA revealed that weight and body composition were both significantly altered in male and female WCs, while remaining unchanged over the three-point measures in NCs. The \% changes in bodyweight in response to 7 days of food restriction (Pre-C measure) and weight recovery 3 weeks later (Post-C measure) were not significantly different between genders.

Pre-C weight loss was $4 \pm 0.3 \%$ of initial bodyweight. Concomitant decreases in fat and LBM were $8 \pm 2.1 \%$ and $3 \pm 0.4 \%$ respectively. There were no gender differences in the amount of fat or LBM lost during weight reduction.

Post-C weight regain was no different between the sexes and represented $4 \pm 0.5 \%$ of bodyweight. However, fat and LBM changes in response to weight recovery were significantly different between the genders. In males, increases in fat and LBM were $7 \pm 2.6 \%$ and $4 \pm 0.9 \%$ respectively. Females, on the contrary, further increased their LBM mass by $4.4 \pm 0.7 \%$, whereas their fat mass did not increase significantly. BMD values remained unchanged over the three-point measures. 


\section{Effects of weight loss and regain on biochemical parameters}

The \% changes in leptin, insulin, cortisol and bone markers in response to Pre- $\mathrm{C}$ weight loss and Post-C weight regain did not reveal any significant differences between the genders. A $4 \%$ bodyweight loss was accompanied by a $64 \%$ decrease in leptin levels $(P<0.001)$, a $31 \%$ decrease in insulin levels $(P<0.0001)$, a $33 \%$ increase in CTx levels $(P<0.0001)$ and a rise in cortisol of $81 \%$ $(P<0.05)$. Osteocalcin and total plasma protein concentrations remained unaffected by weight loss. A $4 \%$ bodyweight regain was accompanied by a $276 \%$ increase in leptin $(P<0.001)$, an $18 \%$ increase in insulin $(P<0.001), \quad$ a $23 \%$ decrease in CTx levels $(P<0.0001)$ and a $27 \%$ drop in cortisol $(P<0.05)$. Osteocalcin and total plasma protein concentrations remained unchanged from Pre-C to Post-C. Changes in leptin, insulin, cortisol, CTx and osteocalcin levels (expressed as \% change) in response to Pre-C weight loss and Post-C weight regain are depicted in Fig. 1.

\section{Correlations between changes in serum leptin with changes in endocrine and anthropometric parameters}

To determine which parameter accounted most for the weight loss-induced increase in bone resorption, a multiple regression analysis was performed in which the decrease in leptin and insulin, and the rise in cortisol were entered as explanatory variables.

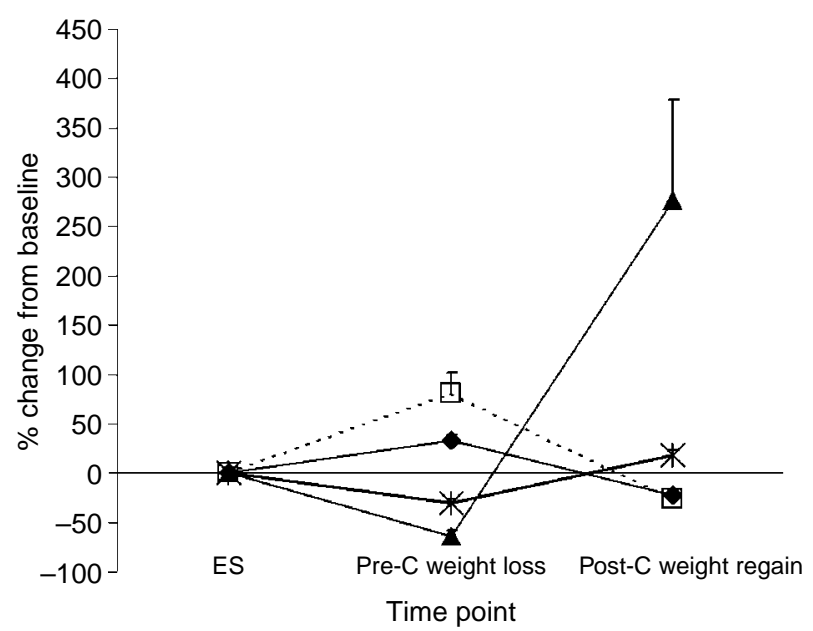

Figure 1 Effects of $4 \%$ bodyweight loss (Pre-C) and $4 \%$ bodyweight regain (Post-C) on serum CTx $(\bullet)$, leptin $(\boldsymbol{\Delta})$, insulin $(*)$ and cortisol $(\square)$ levels (expressed as \% changes). ES versus Pre-C: leptin and insulin levels significantly decreased with weight loss $(P<0.001$ and $P<0.0001$ respectively), whereas CTx and cortisol levels both significantly increased $(P<0.0001$ and $P<0.05$ respectively). Pre-C versus Post-C: leptin and insulin levels significantly increased with weight regain (both $P<0.001$ ), whereas CTx and cortisol levels both significantly decreased $(P<0.0001$ and $P<0.05$ respectively). Osteocalcin and total plasma protein levels were unchanged by Pre- $\mathrm{C}$ weight loss and Post- $\mathrm{C}$ weight regain (not shown on the figure). Data are presented as means \pm S.E.
As a result, the rise in CTx was strongly related to the drop in leptin levels $(r=0.56, P<0.01)$, whereas neither the changes in insulin nor in cortisol participated in the regression analysis. Similarly, the decrease in bone resorption marker with Post-C weight regain was strongly related to the concomitant rise in leptin $(r=0.44, P<0.05)$. No further relationships amongst the changes in the biochemical parameters emerged during weight regain.

To verify if the variance in CTx attributable to changes in leptin were (a) due to changes in fat mass and, if so, (b) how much independent variance was explained by leptin beyond the effects of fat mass per se, both the decrease in fat mass and decrease in leptinaemia were entered into the multiple regression analysis. Changes in leptin in response to both weight loss and weight regain were unrelated to changes in fat mass in both genders. Rather, in both genders, the decrease in leptin during weight reduction was related to bodyweight loss $(r=0.54, P<0.01)$. On the contrary, in both genders the Post-C increase in leptin with weight regain was unrelated to changes in bodyweight or fat mass.

\section{Discussion}

This study examined the relationship between serum leptin, insulin, cortisol, bone biochemical markers and body composition during (a) stable bodyweight, (b) in response to bodyweight reduction and (c) to bodyweight gain. The objective pursued was to add information to the on-going controversy on the effects of leptin on human bone $(2,5,15-17)$. This investigation was based on the assumption that rapid bodyweight variations might concomitantly alter bone metabolism and leptinaemia, thus shedding more light on the inter-relationship between leptin, insulin, cortisol and biochemical markers of bone.

The results of the present study suggest a regulatory role of leptin on type I collagen metabolism and agree with the hypothesis that leptin may inhibit bone resorption (16). The negative association between bone resorption and serum leptin levels observed at baseline (stable bodyweight) was further confirmed by the biochemical changes occurring in responses to weight loss and weight regain. The drop in leptin levels was strongly related to the increase in bone resorption marker occurring in response to weight loss. Similarly, the Post-C rise in leptin levels was associated with a concomitant decrease in bone resorption.

Leptin administration has been shown to inhibit osteoclastogenesis (7) and to increase osteoblastic differentiation of human marrow stromal cells, leading to an increase in the mineralization of the extracellular matrix (6). In vitro evidence supports the hypothesis that leptin is able to directly alter bone remodelling by modulating both osteoblast and osteoclast activities; 
human cross-sectional studies, however, were unable to confirm this. Reports in humans are inconsistent, as negative $(16,18)$ or no $(15)$ associations between circulating leptin levels and bone markers have been reported. The reasons for these discrepancies are still not clear however. The findings of the present study support the notion of a positive effect of leptin on bone, in agreement with animal studies reporting that leptin administration prevented the increase in bone resorption in tailsuspended rats, used as a model of bone loss (8).

In the present study, the role of leptin in the regulation of bone resorption appeared even more salient as, contrary to what could have been expected, potential regulatory candidates such as insulin and cortisol did not yield any association with changes in bone resorption. Leptin has been hypothesized to participate in the activation of the adrenal axis to conserve metabolic fuels in the face of energy deprivation. Glucocorticoids are known to have deleterious effects on bone mass (19), while insulin is thought to act as an anabolic agent on bone (20). In anorectic subjects, a condition of increased bone resorption is consistently accompanied by increased cortisol levels and decreased insulinaemia. Not contradicting this concept, the increased bone resorption observed in the judoists after bodyweight reduction was accompanied by a concomitant rise in cortisol and decrease in insulin. However, the absence of a relationship suggests that neither cortisol nor insulin played a direct role in increasing bone resorption. Greater concentrations of cortisol and longer exposure to hypercortisolaemia might be required for glucocorticoids to exert significant negative effects on bone resorption (19).

Seasonal changes in bone biochemical markers have been described as the result of variable exposure to sunlight (21). Even though overall seasonal changes may be low, accounting for $12 \%$ of the variability of the markers (22), this potential bias had to be questioned when considering the time-frame of the present study (October to March). The 48 judoists were from the same training camp, lived in the same town and were submitted to identical training conditions and environmental influences. Consequently, if seasonal changes in bone resorption were to have occurred, then one would assume that this phenomenon would have affected all the judoists equally. However, serum concentrations of CTx and osteocalcin remained unchanged in the $29 \mathrm{NC}$ judoists throughout the study period. The latter observation confirms the idea that the increase in CTx affecting WCs was indeed attributable to weight loss rather than being an artefact due to seasonal variations in bone markers.

The present findings are in agreement with previous studies reporting an increase in bone resorption with weight loss (23) or acute fasting (24) which have each been demonstrated to cause an increase in bone resorption. Accordingly, refeeding has been shown to decrease resorptive processes (25). However, the mechanisms underpinning these responses are not yet clear. Serum CTx is a validated marker of bone resorption (26) and has the advantage over other markers of being highly specific for bone tissue (27). In some cases, weight loss has also been shown to decrease bone formation (28) but this was not found in our judoists.

The duration and magnitude of the weight loss sustained might not have been sufficient to alter osteocalcin levels. Indeed, osteocalcin is secreted by osteoblasts in the late phase of matrix mineralization, and changes in metabolic activity may thus require a further delay to become visible in the circulation (27).

Even though adipocytes regulate leptin $(o b)$ gene expression and secretion, the dramatic changes in leptin concentrations cannot be accounted for by only the rather modest variations in fat mass. In addition to its adipostatic function, leptin has been proposed to act as a peripheral signal of energy deprivation and has been hypothesized to initiate and regulate the endocrine response to prolonged fasting and starving (2). Leptin has been shown to respond in a dramatic and disproportionate manner to acute and chronic changes in energy balance. Short-term fasting (29) and overeating (30) lead to a rapid decrease and increase, respectively, in leptin synthesis that precedes any weight alterations. Leptin concentrations decline after weight loss (31); weight gain is associated with increased leptin synthesis $(25,32,33)$.

Interestingly, biochemical responses to bodyweight changes were similar in male and female judoists. This may be surprising as leptin is known to exhibit sexual dimorphism. However, in contrast to previous reports in sedentary subjects (16), the gender difference in leptin levels amongst the judoists disappeared when fat mass was introduced as a covariate. This is most likely attributable to the physical fitness of our female subjects. Indeed, sports participation promotes gain in LBM, increased insulin sensitivity, as well as improved fatty acid oxidation and utilization (34). These factors may, in turn, reduce leptin levels or regulate leptin sensitivity in highly trained female athletes (35), thus reducing the discrepancy between males and females.

To conclude, the findings of this study support the hypothesis that leptin has an inhibitory role on bone resorption in humans. Furthermore, in healthy adults, its role in the regulation of bone resorption seems to be more important than the respective contributions of insulin or cortisol. Further investigations are necessary to (a) question the existence of a leptin threshold which may initiate the decrease in bone resorption and (b) to define its potential therapeutic role in the prevention of osteoporosis.

\section{References}

1 Zhang Y, Proenca R, Maffei M, Barone M, Leopold L \& Friedman JM. Positional cloning of the mouse obese gene and its human homologue. Nature 1994372 425-432. 
2 Flier JS. What's in a name? In search of leptin's physiologic role. Journal of Clinical Endocrinology and Metabolism $1998 \mathbf{8 3}$ 1407-1413.

3 Hickey MS, Considine RV, Israel RG, Mahar TL, McCammon MR, Tyndall GL, Houmard JA \& Caro JF. Leptin is related to body fat content in male distance runners. American Journal of Physiology 199634 E938-E940.

4 Halaas JL, Gajiwala KS, Maffei M, Cohen SL, Chait BT, Rabinowitz D, Lallone RL, Burley SK \& Friedman JM. Weight reducing effects of the plasma protein encoded by the ob gene. Science $1995269543-546$.

5 Karsenty G. Leptin controls bone formation through a hypothalamic relay. Recent Progress in Hormone Research 200156 401-415.

6 Thomas T, Gori F, Khosla S, Jensen MD, Burguera B \& Riggs BL. Leptin acts on human marrow stromal cells to enhance differentiation to osteoblasts and to inhibit differentiation to adipocytes. Endocrinology $19991401630-1638$.

7 Holloway WR, Collier FM, Aitken CJ, Myers DE, Hodge JM, Malakellis M, Gough TJ, Collier GR \& Nicholson GC. Leptin inhibits osteoclast generation. Journal of Bone and Mineral Research $200217200-209$.

8 Martin A, de Vittoris R, David V, Moraes R, Begeot M, LafageProust MH, Alexandre C, Vico L \& Thomas T. Leptin modulates both resorption and formation while preventing disuse-induced bone loss in tail-suspended rats. Endocrinology $2005 \mathbf{1 4 6}$ $3652-3659$.

9 Oppliger RA, Steen SA \& Scott JR. Weight loss practices of college wrestlers. International Journal of Sport Nutrition and Exercise Metabolism 200313 117-121.

10 World Health Organisation (WHO). Assessment of fracture risk and its application to screening for postmenopausal osteoporosis. Technical Report Series 843. Geneva, Switzerland, 1994.

11 Greenleaf JE \& Morimoto T. Mechanisms controlling fluid ingestion: thirst and drinking. In Body Fluid Balance: Exercise and Sport, pp 1-17. Eds ER Buskirk \& SM Puhl. New York: CRC Press, 1996.

12 Smith PK, Krohn RI, Hermanson GT, Mallia AK, Gartner FH, Provenzano MD, Fujimoto EK, Goeke NM, Olson BJ \& Klenk DC. Measurement of protein using bicinchoninic acid. Analytical Biochemistry $1985 \mathbf{1 5 0} 76-85$.

13 Favier JC, Ireland-Ripert J, Toque C, Feinberg M. CIQUAL, Centre Informatique sur la Qualité des Aliments, edn 2, Ed. CIQUAL-REGAL. Paris: Lavoisier Technique \& Documentation, 1995.

14 Ambroise M. Apports Nutritionnels Conseillés pour la Population Française, edn 2, Ed. AFSSA, CNERNA-CNRS. Paris: Lavoisier Technique \& Documentation, 2001.

15 Rauch F, Blum WF, Klein K, Allolio B \& Schonau E. Does leptin have an effect on bone in adult women? Calcified Tissue International $199863453-455$.

16 Thomas T, Burguera B, Melton LJ, Atkinson EJ, O'Fallon WM \& Riggs BL. Role of serum leptin, insulin, and estrogen levels as potential mediators of the relationship between fat mass and bone mineral density in men versus women. Bone 200129 114-120.

17 Iwamoto I, Douchi T, Kosha S, Murakami M, Fujino T \& Nagata Y. Relationships between serum leptin level and regional bone mineral density, bone metabolic markers in healthy women. Acta Obstetricia et Gynecologica Scandinavica 200079 1060-1064.

18 Blain H, Vuillemin A, Guillemin F, Durant R, Hanesse B, de Talance N, Doucet B \& Jeandel C. Serum leptin levels is a predictor of bone mineral density in postmenopausal women. Journal of Clinical Endocrinology and Metabolism 200287 1030-1035.

19 Di Somma C, Pivonello R, Loche S, Faggiano A, Marzullo P, Di Sarno A, Klain M, Salvatore M, Lombardi G \& Colao A. Severe impairment of bone mass and turnover in Cushing's disease: comparison between childhood-onset and adult-onset disease. Clinical Endocrinology 200256 153-158.

20 Thrailkill KM, Lumpkin CK Jr, Bunn RC, Kemp SF \& Fowlkes JL. Is insulin an anabolic agent in bone? Dissecting the diabetic bone for clues. American Journal of Physiology, Endocrinology and Metabolism 20055 E735-E745.
21 Pasco JA, Henry MJ, Kotowicz MA, Sanders KM, Seeman E, Pasco JR, Schneider HG \& Nicholson GC. Seasonal periodicity of serum vitamin D and parathyroid hormone, bone resorption, and fractures: the Geelong Osteoporosis Study. Journal of Bone and Mineral Research $200419752-758$.

22 Woitge HW, Scheidt-Nave C, Kissling C, Leidig-Bruckner G, Meyer K, Grauer A, Scharla SH, Ziegler R \& Seibel MJ. Seasonal variation of biochemical indexes of bone turnover: results of a population based study. Journal of Clinical Endocrinology and Metabolism $1998 \mathbf{8 3} 68-75$.

23 Ricci TA, Heymsfield SB, Pierson RN, Stahl T, Chowdhury HA \& Shapes SA. Moderate energy restriction increases bone resorption in obese postmenopausal women. American Journal of Clinical Nutrition 200173 347-352.

24 Grinspoon SK, Baum H, Kim V, Coggins C \& Klibanski A. Decreased bone formation and increased mineral dissolution during acute fasting in young women. Journal of Clinical Endocrinology and Metabolism $1995 \mathbf{8 0} 3628-3633$.

25 Heer M, Mika C, Grzella I, Drummer C \& Herpertz-Dahlmann B. Changes in bone turnover in patients with anorexia nervosa during eleven weeks of in-patient dietary treatment. Clinical Chemistry 20025 745-760.

26 Rosen HN, Moses AC, Garber J, Iloputaife ID, Ross DS, Lee SL \& Greenspan SL. Serum CTx: a new marker of bone resorption that shows treatment effect more often than other markers because of low coefficient of variability and large changes with bisphosphonate therapy. Calcified Tissue International $2000 \mathbf{6 6}$ 100-103.

27 Seibel MJ, Eastell R, Gundberg CM, Hannon R \& Pols HAP. Biochemical markers of bone metabolism. In Principles of Bone Biology, edn 2, pp 1543-1571. Eds JP Bilezikian, LG Raisz \& GA Rodan. San Diego, CA: Academic Press, 2002.

28 Svendsen OL, Hassager C \& Christiansen C. Effect of an energyrestrictive diet, with or without exercise, on lean tissue mass, resting metabolic rate, cardiovascular risk factors, and bone in overweight postmenopausal women. American Journal of Medicine $199395131-140$.

29 Kolaczynski JW, Considine RV, Ohannesian J, Marco C, Opentanova I, Nyce MR, Myint M \& Caro JF. Response of leptin to short-term fasting and refeeding in humans. A link with ketogenesis but not ketones themselves. Diabetes $1996451511-1515$.

30 Kolaczynski JW, Ohannesian JP, Considine RV, Marco CC \& Caro JF. Response of leptin to short-term and prolonged overfeeding in humans. Journal of Clinical Endocrinology and Metabolism 1996 $814162-4165$.

31 Dubuc GR, Phinney DS, Stern JS \& Havel PJ. Changes of serum leptin and endocrine and metabolic parameters after 7 days of energy restriction in men and women. Metabolism $1998 \mathbf{4 7}$ 429-434.

32 Sinha MK, Opentanova I, Ohannesian JP, Kolaczynski JW, Heiman ML, Hale J, Becker GW, Bowsher RR, Stephens TW \& Caro JF. Evidence of free and bound leptin in human circulation - studies in lean and obese subjects and during short-term fasting. Journal of Clinical Investigation 199698 1277-1282.

33 Hebebrand J, Blum WF, Barth N, Coners H, Englaro P, Juul A, Ziegler A, Warnke A, Rascher W \& Remschmidt H. Leptin levels in patients with anorexia nervosa are reduced in the acute stage and elevated upon short-term weight restoration. Molecular Psychiatry 19972 330-334.

34 Ranallo RF \& Rhodes EC. Lipid metabolism during exercise. Sports Medicine $19982629-42$.

35 Thong FS, McLean C \& Graham TE. Plasma leptin in female athletes: relationship with body fat, reproductive, nutritional, and endocrine factors. Journal of Applied Physiology $2000 \mathbf{8 8}$ 2037-2044.

Received 25 October 2005

Accepted 2 December 2005 